\title{
Effects of Acute and Subchronic Exposures to Dimethoate on Rat Cerebral Cortex GABAergic System
}

\author{
Qiang En Wu,, Ting Ting Ban," Xiu Li Chang, Qing Wu, and Zhi Jun Zhou* \\ School of Public Health/Key Laboratory of Public Health and Safety (Ministry of Education), Fudan University, 138 Yixueyuan Road, \\ Shanghai 200032, China
}

(Received July 28, 2009; Accepted February 5, 2010)

\begin{abstract}
The effects of acute and subchronic administration of dimethoate on $\gamma$-aminobutyric (GABA) concentration and receptor characteristics in rat cerebral cortices were investigated. After a single (acute exposure) or repeated administration of dimethoate, rat cerebral cortex was found to inhibit acetylcholinesterase (AChE) activity in a dosedependent manner. No significant alteration in the concentration of GABA or the numbers of $\mathrm{GABA}_{\mathrm{A}}$ receptor was noted in cortices of rats after acute exposure to dimethoate except the affinities of the receptor was found elevated significantly following the acute administration. But the GABA concentrations were significantly reduced in the 10 and $20 \mathrm{mg} / \mathrm{kg}$ groups after the subchronic dimethoate administration. No difference was found statistically in the $\mathrm{GABA}_{\mathrm{A}}$ receptor binding in cortices after the subchronic administration of dimethoate. But the $K_{d}$ values were significant decreased reflecting an elevated affinity of receptors in the three dimethoate groups as compared with that of control follow subchronic administration. It is suggested that the GABAergic system is involved in the intoxication of the dimethoate intoxication which is probably to counteract the enhanced cholinergic activity induced by dimethoate.
\end{abstract}

Key words $-\mathrm{GABA}, \mathrm{GABA}_{\mathrm{A}}$ receptor, dimethoate, subchronic administration

\section{INTRODUCTION}

The acute toxicity of organophosphorus compounds (OPs) are believed to be due primarily to the inhibition of acetylcholinesterase (AChE) resulting in an accumulation of acetylcholine (Ach) with a sustained overstimulation of Ach receptors in the clefts of central and peripheral neuronal synapses. ${ }^{1)}$ The discovery of some neurotransmitters including GABA, and its participation in a number of neurological and behavioral disorders suggest that other systems also may be influenced by organophosphates. ${ }^{2,3)}$

The inhibitory amino acid (IAA) system, which has important physiologic and pathologic roles in anaesthesia and epilepsy, has been neglected in the exploration of mechanisms for OPs intoxication.

\footnotetext{
*To whom correspondence should be addressed: School of Public Health/Key Laboratory of Public Health and Safety (Ministry of Education), Fudan University, 138 Yixueyuan Road, Shanghai 200032, China. Tel.: +86-21-5423-7675; Fax: +86-21-6404-9679; E-mail: zjzhou@ shmu.edu.cn

\#These authors contributed equally to this work.
}

It is well known that GABA is an important inhibitory neurotransmitter in the mammalian central nervous system (CNS). And evidence for neuronal coexistence of the GABAergic system including GABA, $\mathrm{GABA}_{\mathrm{A}}$ receptors, and its uptake system in some cholinergic neurons have been demonstrated in several previous anatomical investigations. ${ }^{4-11)}$ It also has been demonstrated that Ach may regulate GABA synthesis. ${ }^{12-14)}$ Furthermore, other studies have demonstrated the interactions between cholinergic and GABAergic activities in the thalamus, neostriatum, striatum, and hippocampus involved in both physiologic and pathologic conditions. ${ }^{15-19)}$ On long-term exposure, some organophosphorus compounds, such as diisopropylfluorophosphate caused significant changes of $\mathrm{GABA}_{\mathrm{A}}$ receptor following 14 days of treatment. ${ }^{20}$ ) The foregoing evidences indicate that the effects produced by organophosphates include a variety of behavioral and neurological manifestations, all of which can not be attributed to cholinergic hyperactivity solely. Other systems may, in addition or independently, be involved in OPs intoxicatin. ${ }^{20,21)}$ 
Since the alterations of GABAergic system on OPs pesticides intoxication process remains obscured, more remedial approaches are needed to understand the GABAergic mechanisms involved in OPs intoxication. The present paper investigates the alterations of GABAergic system in rat cortex consequent to acute and subchronic dimethoate administration to explore the role of the IAA system in OPs poisoning.

\section{MATERIALS AND METHODS}

Chemicals — Dimethoate, $99 \%$ pure in crystalline form, was a gracious gift from Yunfa Chemical Co., Ltd. (Shanghai, China); GABA, DLhomoserine were purchased from Sigma Chemical Co. (St. Louis, MO, U.S.A.); $O$-phthaladehyde (OPA) and $\beta$-mercaptoethanol (2-MCE) were from Fluka Chemical Co. (Milwaukee, WI, U.S.A.); and $\left[{ }^{3} \mathrm{H}\right]$ GABA $(35 \mathrm{Ci} / \mathrm{mmol})$ was obtained from China Isotope Corporation (Beijing, China). All other chemicals were verified as analytically pure reagents.

Preparation of Solutions - Dimethoate was prepared in saline for acute and subchronic administration. Ice-cold artificial cerebrospinal fluid (ACSF) contained $\mathrm{NaCl} 130 \mathrm{mmol} / \mathrm{l}, \mathrm{KCl}$ $5 \mathrm{mmol} / \mathrm{l}, \quad \mathrm{CaCl}_{2} 2 \mathrm{mmol} / \mathrm{l}, \quad \mathrm{MgSO}_{4} 2 \mathrm{mmol} / \mathrm{l}$, $\mathrm{NaH}_{2} \mathrm{PO}_{4} 1.25 \mathrm{mmol} / \mathrm{l}, \mathrm{NaHCO}_{3} 26 \mathrm{mmol} / \mathrm{l}$, glucose $10 \mathrm{mmol} / \mathrm{l}$, and sucrose $10 \mathrm{mmol} / \mathrm{l}(\mathrm{pH} 7.4)$. The stock solutions of GABA and DL-homoserine as internal standards were prepared at the concentration of $1 \mathrm{mM}$ in filtered $\mathrm{K}_{2} \mathrm{CO}_{3}$ solution $(0.1 \mathrm{~mol} / \mathrm{l})$ containing $50 \%$ high-performance liquid chromatography (HPLC) grade methanol and stored at $-20^{\circ} \mathrm{C}$ for GABA determination. In the stock derivatizing solution, $13.4 \mathrm{mg}$ of OPA was dissolved in $1 \mathrm{ml}$ of dehydrated alcohol and $20 \mu \mathrm{l}$ of 2 -MCE was added. Then the solution was diluted with $4 \mathrm{ml}$ of sodium tetraborate solution $(0.1 \mathrm{~mol} / \mathrm{l}, \mathrm{pH} 9.6)$ and stored protected from light at $4{ }^{\circ} \mathrm{C}$. The stock derivatizing solution can be used for one week by adding $20 \mu \mathrm{l}$ of the 2-MCE daily to maintain the hydrosulfide concentration. All of the working solutions were freshly diluted from stock solutions.

Animals — Male adult Sprague-Dawley rats (24 SD rats of 7 weeks old weighted $200 \pm 20 \mathrm{~g}$ for acute administration; 24 SD rats of 6 weeks old weighted $160 \pm 20 \mathrm{~g}$ for subchronic administration) were obtained from the Animal Research Center of Fudan University. All of the animals were randomly di- vided into four groups with 6 rats per group for both acute and subchronic treatments. The animals were conditioned in a temperature-controlled environment with a 12/12-hr light/dark cycle and allowed free access to water and food for 1 week before the experiment started. Animals were maintained in accordance with the principles stated in the Guidelines for the Care and Use of Laboratory Animals of the National Institutes of Health (U.S.A.) as well as Fudan University.

Administration of Dimethoate — In the acute treatments, a single dimethoate dose of 38.9, 83.7, or $180.0 \mathrm{mg} / \mathrm{kg}$ was administered via oral gavage in volumes of $10 \mathrm{ml} / \mathrm{kg}$. The treated rats were sacrificed by decapitation $8 \mathrm{hr}$ after the treatment. In subchronic treatments, a dose of $5\left(0.02 \mathrm{LD}_{50}\right), 10$ $\left(0.08 \mathrm{LD}_{50}\right)$, or $20 \mathrm{mg} / \mathrm{kg}\left(0.32 \mathrm{LD}_{50}\right)$ was administered via oral gavage in volumes of $10 \mathrm{ml} / \mathrm{kg}$ body weight (bw) for 90 days except weekends. Both saline-treated control and dimethoate treated animals were sacrificed at the same time. Cortices from all of the animals were prepared for neurochemical determination and $\mathrm{GABA}_{\mathrm{A}}$ receptor binding assays. All animal experimental procedures were performed between 9:00 and 14:00 in the project.

Observation of Animals — All animals were observed for overt neurobehavioral function status before and after acute and chronic dimethoate administrations. Specific signs according to OP poisoning, such as salivation, fasciculations, tremors, facial movements, head clonus, forelimb clonus, chewing, and straub tail were extensively observed and recorded.

Determination of AChE Activity — The AChE activity was determined according to the procedure of Ellman's colorimetric method. ${ }^{22)}$ Briefly, a $30 \mu 1$ of aliquot of homogenate was added to $3 \mathrm{ml}$ phosphate buffer containing 5,5'-dithio-bis-nitrobenzoic acid (DTNB) and Thioacetyl-choline iodide (ASCh) and incubated in $37^{\circ} \mathrm{C}$ water bath for $6 \mathrm{~min}$, and then the activity was determined using a visible range spectrophotometer (Unico, Shanghai, China) at a wavelength of $412 \mathrm{~nm}$. The AChE activity was expressed as micromoles of ASCh hydrolyzed by one gram of protein ( $\mu \mathrm{mol} / \mathrm{g}$ protein).

Neurochemical Determinations__ Following decapitation, the rat brains were quickly removed and the cerebral cortices were dissected above an ice box as quickly as possible. The samples were frozen in liquid nitrogen and stored at $-80^{\circ} \mathrm{C}$ until analysis. The cerebral cortices were homogenized with $8-10$ strokes using a glass 
homogenizer in ice-cold ACSF $(1: 9$, w/v). The homogenates were collected and centrifuged at $4^{\circ} \mathrm{C}$ for $15 \mathrm{~min}$ at $3000 \mathrm{rpm}$ for subsequent $\mathrm{AChE}$ activity, GABA concentrations and total protein assays. For the $\left[{ }^{3} \mathrm{H}\right]$ GABA binding assays, the cerebral cortices were homogenized in ice-cold sucrose solution $(0.32 \mathrm{~mol} / \mathrm{l}, \mathrm{pH} 7.4,1: 9, \mathrm{w} / \mathrm{v})$ for synaptic membrane preparation. The homogenate was centrifuged at $1000 \mathrm{~g}$ for $10 \mathrm{~min}$ at $4^{\circ} \mathrm{C}$. The supernatant was collected and centrifuged for $20 \mathrm{~min}$ at $20000 \mathrm{~g}$. The pellet was resuspended in $50 \mathrm{mM}$ Tris- $\mathrm{HCl}$ buffer $(\mathrm{pH}$ 7.4) and centrifuged at $48000 \mathrm{~g}$ for $30 \mathrm{~min}$. The last step was repeated once. The resulting pellet was frozen and stored at $-70^{\circ} \mathrm{C}$ for at least $18 \mathrm{hr}$ before use. On the experiment day, membrane pellets were thawed at $4^{\circ} \mathrm{C}$ and resuspended in 2 to 3 volumes $(\mathrm{v} / \mathrm{v})$ of Tris- $\mathrm{HCl}$ buffer containing $0.05 \%$ Triton X-100 before centrifugation at $48000 \mathrm{~g}$ for $30 \mathrm{~min}$. The final pellet was then resuspended in Tris- $\mathrm{HCl}$ buffer to a final concentration of $200-350 \mu \mathrm{g} / \mathrm{ml}$ and used for next binding assays.

Determination of GABA Levels in the Cerebral Cortices_- After homogenization and centrifugation, the amino acids in prepared supernatants were derivatized in the working derivitizing solution containing OPA and 2-MCE under room temperature for $2 \mathrm{~min}$. Then the GABA and internal standard were separated with a HP-1100 HPLC system and be detected at a fluorescence detector (Hewlett-Packard, Boeblingen, Germany) using isocratic elution as previously described. ${ }^{23)}$ A Hypersil octadecyl silica (ODS) 3 column $(4.6 \times 250 \mathrm{~mm}$, $5 \mu \mathrm{m}$, GL, Kyoto, Japan) was used in the HPLC system. The mobile phase was potassium dihydrogen phosphate buffer $(0.1 \mathrm{~mol} / \mathrm{l}, \mathrm{pH} 6.0)$ containing $30 \%$ methanol and $10 \%$ acetonitrile delivered at a flow rate of $1.0 \mathrm{ml} / \mathrm{min}$ which was filtered through a $0.2 \mu \mathrm{m}$ nylon membrane and degassed by ultrasonification before use. DL-homoserine was served as the internal standard for further quantification. The detection limit was $0.01 \mu \mathrm{mol} / 1$ for GABA in the HPLC system with an inner-day variation of $3.44 \%$ and inter-day variation of $9.58 \%$.

$\left[{ }^{3} \mathbf{H}\right]$ GABA Binding Assays — The binding assays were performed in duplicate in a final volume of $300 \mu \mathrm{l}$ of buffer at room temperature for $45 \mathrm{~min}$ as described by Enna and Synder ${ }^{24)}$ with minor modifications of six increasing concentrations of $\left[{ }^{3} \mathrm{H}\right]$ GABA ranging from $0.05 \mathrm{nM}$ to $60 \mathrm{nM}$. Nonspecific binding was determined in the presence of $5 \mathrm{mM}$ of unlabeled GABA. The incubation was terminated by rapid filtration through glass fiber filters pretreated with $0.15 \%$ polyethyleneimine for at least $2 \mathrm{hr}$ to reduce filter binding. The radioactivity retained on the filters was counted with liquid scintillation spectrometry.

\section{Determination of Protein Concentration}

The supernatant was collected after centrifugation at $3000 \mathrm{rpm}$ and the total protein concentration was measured by the method of bicinchoninic acid kit according to the instructions of the manufacturer (Beyotime, Jiangsu, China) using bovine serum albumin as a standard.

Data Analysis — AChE activity, GABA concentration, and densities and affinities of $\mathrm{GABA}_{\mathrm{A}}$ receptors are expressed as mean \pm S.D. in the percentages of controls' values. For the binding assays, the $B_{\max }$ (maximum binding capacity) and $K_{d}$ (equilibrium dissociation constant) values of $\mathrm{GABA}_{\mathrm{A}}$ receptor were determined by computerized Scatchard analysis with nonlinear regression (GraphPad Prism Program, version 4.0, San Diego, CA, U.S.A.). All other statistical analyses were performed with oneway analysis of variance (ANOVA) followed by Dunnett's post-hoc tests using SPSS (version 12) software and $p<0.05$ between two means was considered significant statistically.

\section{RESULTS}

\section{Effect of Dimethoate on the Gross Behavioral Activity and on AChE Activity}

Acute administration of dimethoate in all doses induced typical signs of OPs-induced toxicity, which included weakness, salivation, fasciculations, tremor, facial movements, and head and forelimb clonus. Severe manifestations, such as unconsciousness, incontinence, and convulsions, were noted in rats from the dimethoate group $180 \mathrm{mg} / \mathrm{kg}$ bw. On chronic administration of dimethoate, only animals in 10 or $20 \mathrm{mg} / \mathrm{kg}$ doses exhibited some symptoms including salivation, secretion around eyes. No death occurred during both the acute and subchronic experimental period.

AChE activities were significantly reduced both after acute and subchronic treatments. Significant inhibition of AChE activity in the rat cerebral cortex was observed at all doses of dimethoate in a dosedependent manner in the acute assay (Fig. 1). The percentages of AChE activities in the 38.9, 83.7, and $180.0 \mathrm{mg} / \mathrm{kg}$ bw groups were $43.0 \%(p<0.05)$, $34.0 \%(p<0.05)$, and $25.0 \%(p<0.05)$ as com- 


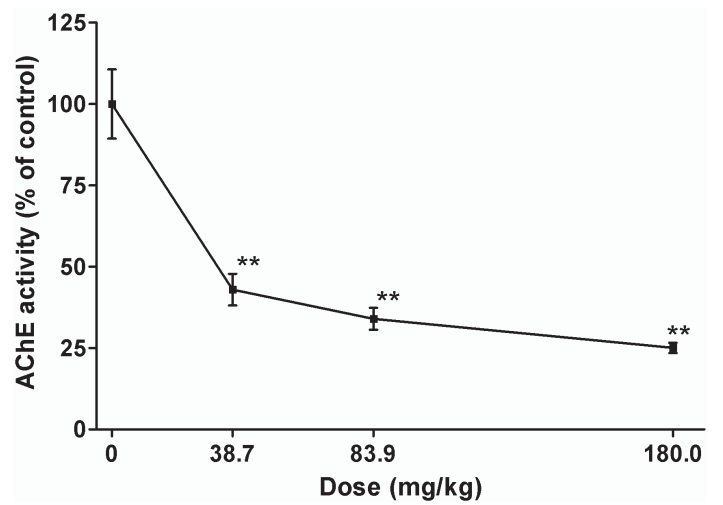

Fig. 1. Cortical AChE Activities at $8 \mathrm{hr}$ after Dimethoate Administration

Rats were administrated with dimethoate (38.9, 83.7, and $180.0 \mathrm{mg} / \mathrm{kg} \mathrm{bw}$ ) or saline via gavage. Data were presented as percentage of control and mean \pm S.D. were given $(n=6)$ for each group. ${ }^{* *} p<0.01$ compared to the control group.

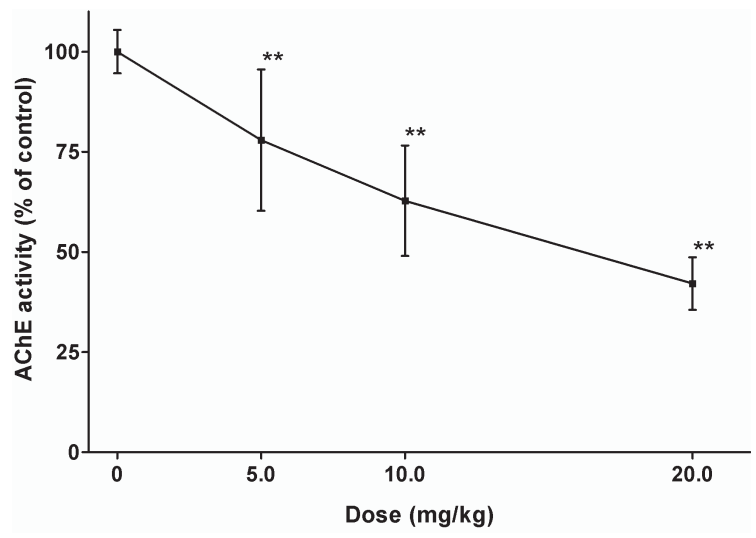

Fig. 2. Cortical AChE Activities after 90-day Dimethoate Administration

Rats have been treated with dimethoate $(5.0,10.0$, and $20.0 \mathrm{mg} / \mathrm{kg}$ bw) or saline via gavage for 90 days. Data were presented as mean \pm S.D. of percentages of control. ${ }^{* *} p<0.01$ compared to the control in one-way analysis of variance followed by Dunnett's post-hoc tests.

pared with controls, respectively. And AChE activities were significantly reduced dose dependently after subchronic treatment of dimethoate too at the end of treatment (Fig. 2). The percentages of the AChE activity values were reduced by $22.1 \%(p<$ $0.05), 37.2 \%(p<0.05)$, and $57.9 \%(p<0.05)$ of controls in the dimethoate $5.0,10.0$, and $20.0 \mathrm{mg} / \mathrm{kg}$ bw groups, respectively.

\section{GABA Concentrations in Rat Cerebral Cortices Following Acute and Subchronic Administration of Dimethoate}

GABA concentrations observed in the rat cerebral cortices after the acute and subchronic

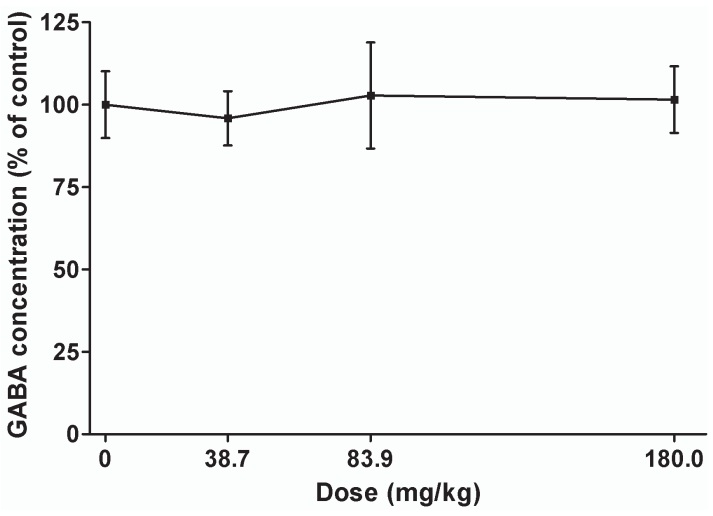

Fig. 3. GABA Concentrations in Rat Cerebral Cortex at $8 \mathrm{hr}$ after Dimethoate Administration

Rats were administrated with dimethoate $(38.9,83.7$, and $180.0 \mathrm{mg} / \mathrm{kg} \mathrm{bw}$ ) dissolved in saline via gavage. Control rats were treated with saline in the same volume. Data were presented as percentage of control and mean \pm S.D. were given $(n=6)$ for each group. The GABA concentrations were $95.87 \%(p>0.05), 102.80 \%(p>0.05)$, and $101.55 \%(p>0.05)$ of control in the dimethoate-treated groups, respectively.

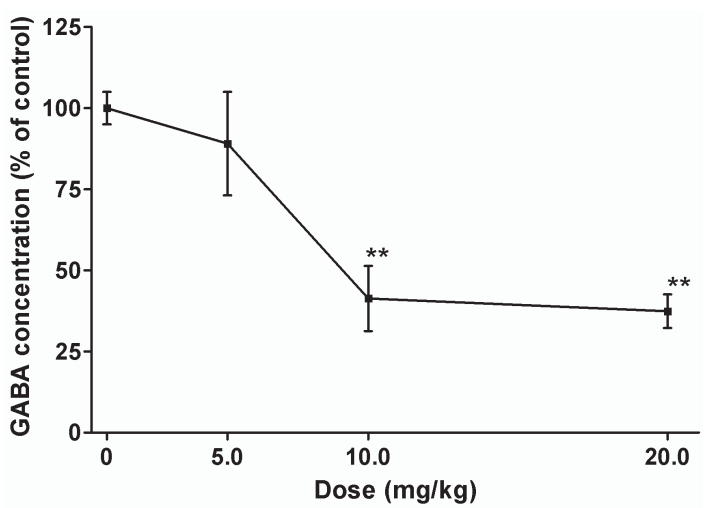

Fig. 4. GABA Concentrations in Rat Cerebral Cortex after 90day Dimethoate Administration

Rat have been treated with dimethoate $(5.0,10.0$, and $20.0 \mathrm{mg} / \mathrm{kg}$ bw) or saline via gavage for 90 days. Data were presented as mean \pm S.D. of percentages of control. ${ }^{* *}$ Values significantly different from controls, by one-way ANOVA and Dunett's post-hoc tests $(p<0.01)$.

dimethoate administration were showed in Figs. 3 and 4, respectively. Following acute administration of dimethoate, the levels of GABA showed no significant changes in rat cerebral cortices as compared to the control group. The GABA concentrations were $95.87 \%(p>0.05), 102.80 \%(p>0.05)$, and $101.55 \%(p>0.05)$ of control in three acute dimethoate-treated groups, respectively. For subchronic administration, the GABA concentration in the $5.0 \mathrm{mg} / \mathrm{kg}$ bw group represented a mild decrease but it did not reach significance statistically $(89.08 \%$ of control, $p>0.05$ ) compared with the control. 


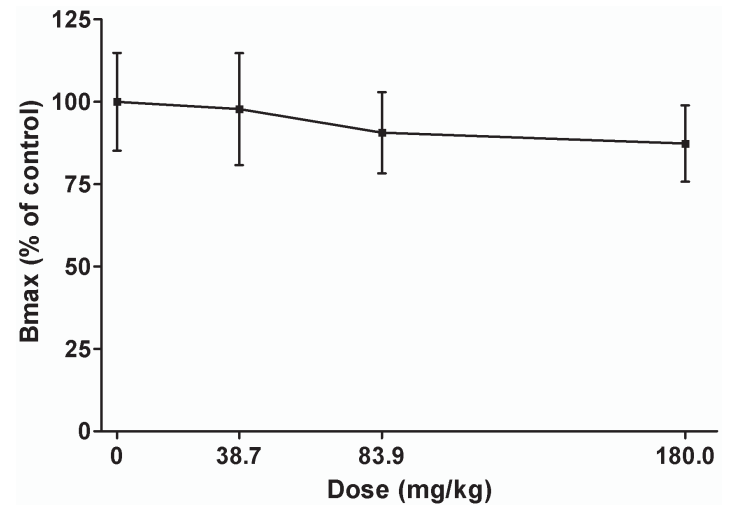

Fig. 5. The $B_{\max }$ Values of $\left[{ }^{3} \mathrm{H}\right]-\mathrm{GABA}$ Binding to Cortical Synaptic Membranes from Rats Treated with Dimethoate $(38.9,83.7$, and $180.0 \mathrm{mg} / \mathrm{kg}$ ) or saline $8 \mathrm{hr}$ Membranes were incubated with ligand concentrations ranging from 0.05 to $60 \mathrm{nmol} / 1$. Values indicated represent mean \pm S.D. of three independent experiments. No significant changes were observed compared to controls statistically. The $B_{\max }$ value of GABA receptors was $6.47 \pm 0.96 \mathrm{pmol} / \mathrm{mg}$ for the acute control group.

However, the GABA concentrations were significantly reduced in the top two highest dosed groups after the subchronic dimethoate administration. The levels of the neurotransmitter were $41.33 \%$ ( $p<$ $0.05)$ and $37.44 \%(p<0.05)$ of control in the dimethoate 10 and $20.0 \mathrm{mg} / \mathrm{kg}$ bw groups, respectively.

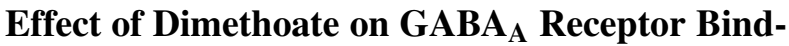 ing after Dimethoate Administration}

Although a mild decrease of $\mathrm{GABA}_{\mathrm{A}}$ receptor binding in cortical synaptic membranes was observed in the treated groups as determined by Scatchard analysis, no difference was found statistically in the treated groups after the acute treatment with dimethoate. The numbers of binding sites were $97.79 \%(p>0.05), 90.63 \%(p>0.05)$, and $87.33 \%(p>0.05)$ of control in the dimethoate 38.9 , $83.7 \mathrm{mg} / \mathrm{kg}$, and $180.0 \mathrm{mg} / \mathrm{kg}$ groups as compared to that of the control, respectively (Fig. 5). Similarly, the $B_{\max }$ value of the three dimethoate-treated groups also represented a slightly decrease as compared to the control while no significance was observed in all of them after subchronic administration of dimethoate ( $p>0.05$, Fig. 6).

Effects of Dimethoate Administration on the Affinities $\left(K_{d}\right)$ of $\mathrm{GABA}_{\mathrm{A}}$ Receptors in Rat Cerebral Cortices

Eight hours following dimethoate administration, decrease in the $K_{d}$ values was observed without statistical significance ( $85.33 \%$ of control, $p>$

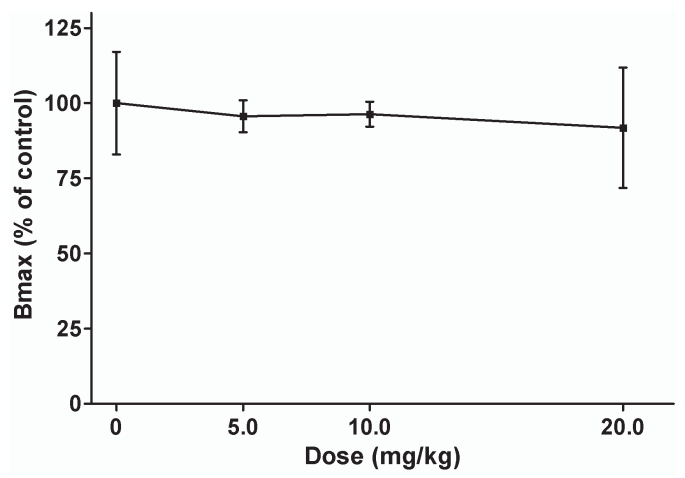

Fig. 6. The $B_{\max }$ Values of $\left[{ }^{3} \mathrm{H}\right]-\mathrm{GABA}$ Binding to Cortical Synaptic Membranes from Rats Treated with Dimethoate $(5,10$, and $20 \mathrm{mg} / \mathrm{kg}$ ) or Saline for 90 Days

Membranes were incubated with ligand concentrations ranging from 0.05 to $60 \mathrm{nmol} / \mathrm{l}$. Values indicated represent mean \pm S.D. of three independent experiments. The $B_{\max }$ of controls was $6.18 \pm 1.83 \mathrm{pmol} / \mathrm{mg}$ protein. The $B_{\max }$ values of the three treated groups were $95.63 \%(p>0.05), 96.33 \%(p>0.05)$, and $91.80 \%$ $(p>0.05)$ of controls respectively.

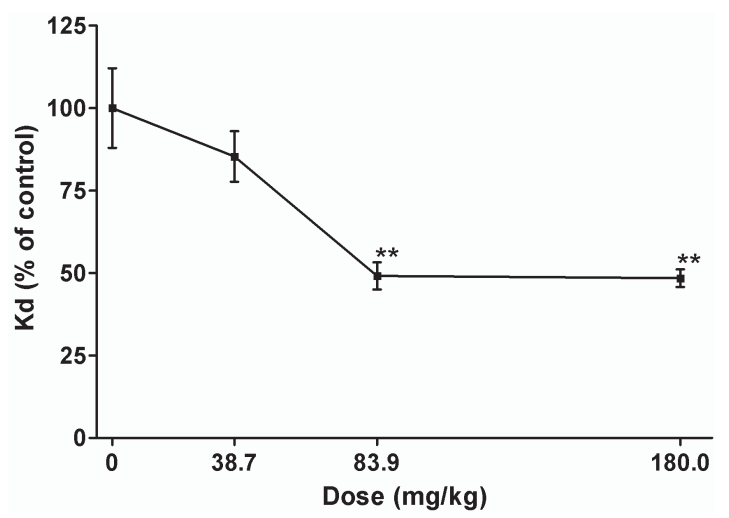

Fig. 7. The $K_{d}$ Values of $\left[{ }^{3} \mathrm{H}\right]-\mathrm{GABA}$ Binding to Cortical Synaptic Membranes from Rats Treated with Dimethoate $(38.9,83.7$, and $180.0 \mathrm{mg} / \mathrm{kg}$ ) or Saline

Membranes were incubated with ligand concentrations ranging from 0.05 to $60 \mathrm{nmol} / 1$. Values indicated represent mean \pm S.D. of three independent experiments. ${ }^{* *}$ Values significantly different from controls by one-way ANOVA and Dunett's post-hoc tests $(p<0.01)$.

0.05 ) in the group of $38.9 \mathrm{mg} / \mathrm{kg}$ dimethoate in the cortical membranes as shown in Fig. 7. But the percentages of the value were reduced significantly to $49.13 \%(p<0.05)$ and $48.47 \%(p<0.05)$ of control in the 83.7 and $180.0 \mathrm{mg} / \mathrm{kg}$ dimethoate groups, respectively. Subsequently, there were significant decreases in the three dimethoate groups with percentages of $63.90 \%(p<0.05), 40.47 \%(p<0.05)$, and $43.80 \%(p<0.05)$ of controls for the $K_{d}$ values as compared with that of control after subchronic administration (Fig. 8). 


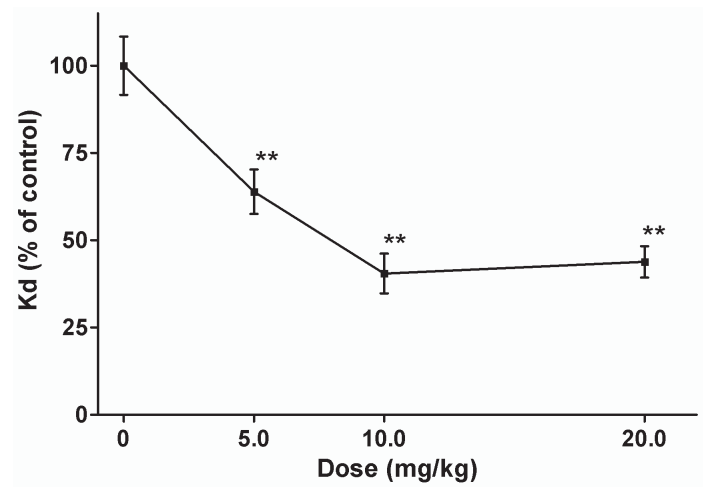

Fig. 8. The $K_{d}$ Values of $\left[{ }^{3} \mathrm{H}\right]-\mathrm{GABA}$ Binding to Cortical Synaptic Membranes from Rats Treated with Dimethoate $(5,10$, and $20 \mathrm{mg} / \mathrm{kg}$ ) or Saline for 90 Days Membranes were incubated with ligand concentrations ranging from 0.05 to $60 \mathrm{nmol} / \mathrm{l}$. Values indicated represent mean \pm S.D. of three independent experiments. ${ }^{* *}$ Values significantly different from controls $(94.09 \pm 7.85 \mathrm{nmol} / \mathrm{l})$, by one-way ANOVA and Dunett's post-hoc tests $(p<0.01)$.

\section{DISCUSSION}

Cholinergic mechanism plays a vital role in OPs-induced intoxication. The relationships between the cholinergic and amino acid neurotransmitter systems, especially the excitatory amino acid (EAA) system, have been implied by some experimental studies. ${ }^{25,26)}$ But an imbalance between EAA and IAA systems is associated with many diseases. ${ }^{27,28)}$ GABA is recognized as the principal inhibitory neurotransmitters in the cerebral cortex. ${ }^{29)}$ In the present study, we examined the alterations in GABA levels and $\mathrm{GABA}_{\mathrm{A}}$ receptors characteristics following acute and subchronic dimethoate administration to elucidate the noncholinergic mechanisms involved in OPs intoxication.

In the present study, the activities of $\mathrm{AChE}$ were reduced in a dose-dependent manner significantly following the acute dimethoate administration. While the GABA in rat cerebral cortices did not show statistical change in the three dosed groups compared to the control group after a single injection of dimethoate. But Shih and McDonough reported that GABA concentrations reached significantly high levels in the hippocampus, cortex and striatum after seizure onset following acute soman intoxication. ${ }^{26)}$ Similarly, remarkable increase in extracellular striatal levels of GABA concentrations was observed in rats with severe signs of poisoning after soman administration. ${ }^{30)}$ But these findings do not seem correlated well with our observations that the GABA neurotransmitter did not changed significantly after the acute dimethoate administration. It may be caused by the significant different toxicities of the two organophosphates. Dimethoate is a general use organophosphorus insecticide and be defined as a moderately toxic compound in U.S. Environmental Protection Agency (EPA) toxicity class II. While soman, one of the organophosphorus nerve agents used in chemical warfare, is exceedingly lethal to mammalian. In addition, no statistical significance of the numbers of $\mathrm{GABA}_{\mathrm{A}}$ receptor binding sites in cortices was observed after the acute dimethoate exposure too. However, the $K_{d}$ values were significantly reduced in the 83.7 and $180.0 \mathrm{mg} / \mathrm{kg}$ dimethoate groups as compared to that of control, that is, the affinities were elevated following the acute exposure to high dose of dimethoate. But Townsend reported that no significant alteration in GABA receptor affinity was noted in visual cortex of cats following an acute exposure to the organophosphorus compound diisopropylfluorophosphate. ${ }^{31)}$ This discordance probably results from the species and test substance differences in the two studies. The elevated affinities of $\mathrm{GABA}_{\mathrm{A}}$ receptors observed in the present study probably reflect an increased inhibitory response in an attempt to overcome the heightened neuronal excitation during the course of acute OPs intoxication.

Unlike the result after the acute dimethoate intoxication, the GABA concentration was reduced significantly in rat cortices both at the 10 and $20 \mathrm{mg} / \mathrm{kg}$ dimethoate groups treated subchronically. Prolonged exposure to dimethoate resulted in more noticeable alterations in GABA contents in rat cortices than acute intoxication. The decreased manifestation of GABA contents after long term dimethoate exposure can be explained in several possible ways: physiologically GABAergic system coexisted with cholinergic system in various brain regions of the rat. ${ }^{7,9-11)}$ Both GABA and Ach can regulate each other's metabolism in many regions of rat brain. ${ }^{18,32)}$ It might be believed the hyperactivity of the cholinergic system would recruit the modulation on the metabolism of the GABAergic system following long term OPs administration. GABA is formed by the decarboxylation of glutamate, a primary excitatory amino acid neurotransmitter in CNS, by glutamic acid decarboxylase in GABAergic terminals. The excitatory effect of the accumulated Ach in chronic dimethoate intoxication might reduce glutamate contents to prevent additional damage from excitotoxicity, which will decrease GABA synthesis subsequently. Another possible pathway is that the enhanced GABA recep- 
tor's affinity will probably reduce the synthesis of GABA in CNS compensaterily. Besides those, it also has the possibility that the GABA would be degrade or reuptake more efficiently after long term OPs exposure which would contribute to the decrease of GABA in the intoxication. But further precise mechanisms of GABA metabolism involved in dimethoate intoxication still need more investigation.

Furthermore, no significant alteration was noted in the numbers of $\mathrm{GABA}_{\mathrm{A}}$ receptor in rat cortices following the subchronic administration. However, the affinities significantly elevated by all three doses as compared to control after the subchronic exposure to dimethoate, which is similar with that of acute treatment with high doses of dimethoate in the study. On the basis of current findings, it can be hypothesized that an accumulation of Ach caused by OPs poisoning would induce the increase of the affinities of $\mathrm{GABA}_{\mathrm{A}}$ receptor in rat cortices following both acute and subchronic dimethoate exposure the increased $\mathrm{GABA}_{\mathrm{A}}$ receptor affinities will protect neurons from the hyperactivity of excessive Ach in the intoxication. Although dimethoate might act on $\mathrm{GABA}_{\mathrm{A}}$ receptor directly, it is still hard to define whether the decreased $\mathrm{GABA}_{\mathrm{A}}$ receptor $K_{d}$ values were induced by direct or indirect actions on the receptors by dimethoate currently. Further experiments are needed to elucidate this hypothesis with selective agonists or antagonists for each neurotransmitter system after dimethoate administration.

The results of our study suggested an involvement of GABAergic system in the intoxication of the organophosphate dimethoate besides the alteration in cholinergic system in the cortex of rats after acute and subchronic exposure to dimethoate. It indicated that the difference in the contents of GABA neurotransmitter in rat cerebral cortex after acute and subchronic administration of dimethoate. And an elevated affinity of $\mathrm{GABA}_{\mathrm{A}}$ receptor in rat cortex under subchronic exposure probably is to counteract the enhanced cholinergic activity induced by dimethoate.

Acknowledgements The study was conducted under grants from the Nature Science Foundation of China (No. 30571554) and the National Key Technology R\&D Program in the $11^{\text {th }}$ Five-year Plan of China (No. 2006BAI06B01). Thanks are due to Mr. Lixing Zheng, Mr. Gaoren Zhong and Ms. Guoying Zhu for their excellent technical assistance.

\section{REFERENCES}

1) Tuovinen, K. (2004) Organophosphate-induced convulsions and prevention of neuropathological damages. Toxicology, 196, 31-39.

2) Corrigan, F. M., MacDonald, S., Brown, A., Armstrongm, K. and Armstrong, E. M. (1994) Neurasthenic fatigue, chemical sensitivity and GABAa receptor toxins. Med. Hypotheses, 43, 195200.

3) Chebabo, S. R., Santos, M. D. and Albuquerque, E. X. (1999) The organophosphate sarin, at low concentrations, inhibits the evoked release of GABA in rat hippocampal slices. Neurotoxicology, 20, 871882.

4) Alkondon, M., Pereira, E. F. R., Eisenberg, H. M. and Albuquerque, E. X. (1999) Choline and selective antagonists identify two subtypes of nicotinic acetylcholine receptors that modulate GABA release from CA1 interneurons in rat hippocampal slices. $J$. Neurosci., 19, 2693-2705.

5) Ikarashi, Y., Yuzurihara, M., Takahashi, A., Ishimaru, H. and Maruyama, Y. (1999) Neurochemical determination of the location of NMDA and GABA receptors on rat striatal cholinergic neurons. Brain Res. Brain Res. Protoc., 4, 378-382.

6) Gao, B., Hornung, J. P. and Fritschy, J. M. (1995) Identification of Distinct GABA(A)-Receptor Subtypes in Cholinergic and Parvalbumin-Positive Neurons of the Rat and Marmoset Medial Septum - Diagonal Band Complex. Neuroscience, 65, 101-117.

7) Bonanno, G. and Raiteri, M. (1987) Presence of a gamma-aminobutyric acid (GABA) uptake system on cholinergic terminals of rat hippocampus: evidence for neuronal coexistence of acetylcholine and GABA? J. Pharmacol. Exp. Ther, 240, 294-297.

8) Beaulieu, C. and Somogyi, P. (1991) Enrichment of cholinergic synaptic terminals on GABAergic neurons and coexistence of immunoreactive GABA and choline acetyltransferase in the same synaptic terminals in the striate cortex of the cat. J. Comp. Neurol., 304, 666-680.

9) Moragues, N., Ciofi, P., Tramu, G. and Garret, M. (2002) Localisation of GABA(A) receptor epsilonsubunit in cholinergic and aminergic neurones and evidence for co-distribution with the theta-subunit in rat brain. Neuroscience, 111, 657-669.

10) Ito, T., Iino, S. and Nojyo, Y. (2005) A part of cholinergic fibers in mouse superior cervical ganglia contain GABA or glutamate. Brain Res., 1046 (1-2), 234-238.

11) Kosaka, T., Tauchi, M. and Dahl, J. L. (1988) Cholinergic neurons containing GABA-like and/or 
glutamic acid decarboxylase-like immunoreactivities in various brain regions of the rat. Exp. Brain Res., 70, 605-617.

12) Michel, F. J., Fortin, G. D., Martel, P., Yeomans, J. and Trudeau, L.-E. (2005) M3like muscarinic receptors mediate $\mathrm{Ca} 2+$ influx in rat mesencephalic GABAergic neurones through a protein kinase C-dependent mechanism. Neuropharmacology, 48, 796-809.

13) Michel, F. J., Robillard, J. M. and Trudeau, L.-E. (2004) Regulation of rat mesencephalic GABAergic neurones through muscarinic receptors. J. Physiol. (Pt 2), 556, 429-445.

14) Lena, C., Changeux, J. P. and Mulle, C. (1993) Evidence for "preterminal" nicotinic receptors on GABAergic axons in the rat interpeduncular nucleus. J. Neurosci., 13, 2680-2688.

15) Dewey, S. L., Smith, G. S., Logan, J. and Brodie, J. D. (1993) Modulation of central cholinergic activity by GABA and serotonin: PET studies with 11C-benztropine in primates. Neuropsychopharmacology, 8, 371-376.

16) Behrends, J. C. and ten Bruggencate, G. (1993) Cholinergic modulation of synaptic inhibition in the guinea pig hippocampus in vitro: excitation of GABAergic interneurons and inhibition of GABArelease. J. Neurophysiol., 69, 626-629.

17) Scatton, B. and Bartholini, G. (1980) Modulation by GABA of cholinergic transmission in the striatum. Brain Res., 183, 211-216.

18) Rowell, P. P., Volk, K. A., Li, J. and Bickford, M. E. (2003) Investigations of the cholinergic modulation of GABA release in rat thalamus slices. Neuroscience, 116, 447-453.

19) Koos, T. and Tepper, J. M. (2002) Dual cholinergic control of fast-spiking interneurons in the neostriatum. J. Neurosci., 22, 529-535.

20) Sivam, S. P., Norris, J. C., Lim, D. K., Hoskins, B. and Ho, I. K. (1983) Effect of acute and chronic cholinesterase inhibition with diisopropylfluorophosphate on muscarinic, dopamine, and GABA receptors of the rat striatum. J. Neurochem., 40, 1414-1422.

21) Myhrer, T., Nguyen, N. H. T., Andersen, J. M. and Aas, P. (2004) Protection against soman-induced seizures in rats: relationship among doses of prophylactics, soman, and adjuncts. Toxicol. Appl. Pharmacol., 196, 327-336.
22) Ellman, G. L., Courtney, K. D., Andres, V. and Feather-Stone, R. M. (1961) A new and rapid colorimetric determination of acetylcholinesterase activity. Biochem. Pharmacol., 7, 88-95.

23) Wu, Q. E., Ban, T. T., Chang, X. L., Jin, T. Y., Liang, Y. X., Wu, Q. and Zhou, Z. J. (2007) Involvement of the GABAergic System in Dimethoate-induced Intoxication. J. Health Sci., 53, 527-533.

24) Enna, S. J. and Snyder, S. H. (1975) Properties of gamma-aminobutyric acid (GABA) receptor binding in rat brain synaptic membrane fractions. Brain Res., 100, 81-97.

25) Casida, J. E. and Quistad, G. B. (2004) Organophosphate toxicology: Safety aspects of nonacetylcholinesterase secondary targets. Chem. Res. Toxicol., 17, 983-998.

26) Shih, T. M. and McDonough, J. H. J. (1997) Neurochemical mechanisms in soman-induced seizures. $J$. Appl. Toxicol., 17, 255-264.

27) Garcia-Alloza, M., Tsang, S. W., Gil-Bea, F. J., Francis, P. T., Lai, M. K., Marcos, B., Chen, C. P. and Ramirez, M. J. (2006) Involvement of the GABAergic system in depressive symptoms of Alzheimer's disease. Neurobiol. Aging, 27, 11101117.

28) Materi, L. M. and Semba, K. (2001) Inhibition of synaptically evoked cortical acetylcholine release by intracortical glutamate: involvement of GABAergic neurons. Eur. J. Neurosci., 14, 38-46.

29) Schwartz, R. D. (1988) The GABAA receptor-gated ion channel: biochemical and pharmacological studies of structure and function. Biochem. Pharmacol., 37, 3369-3375.

30) Cassel, G. E. and Fosbraey, P. (1996) Measurement of the oxime HI-6 after peripheral administration in tandem with neurotransmitter levels in striatal dialysates: Effects of soman intoxication. J. Pharmacol. Toxicol. Methods, 35, 159-166.

31) Townsend, A. T., Adams, D. K., Lopez, J. B. and Kirby, A. W. (1991) Effect of Diisopropylfluorophosphate on Muscarinic and GammaAminobutyric-Acid Receptors in Visual-Cortex of Cats. Life Sci., 49, 1053-1060.

32) Anderson, J. J., Kuo, S., Chase, T. N. and Engber, T. M. (1993) GABAA and GABAB receptors differentially regulate striatal acetylcholine release in vivo. Neurosci. Lett., 160, 126-130. 